\title{
O OUVIDO, A BOCA E O OLHO: A PSICANÁLISE ENTRE $O$ APAGAMENTO E A MEMÓRIA DOS LUGARES DA LINGUAGEM
}

Alessandra Caneppele

Psicóloga,

psicanalista, mestre (FFLCHUSP) e doutora (IFCH-Unicamp) em epistemologia da psicanálise; pós-doutoranda no Departamento de Lingüística do IEL-Unicamp (bolsa Fapesp).

\begin{abstract}
RESUMO: Em Entwurf einer Psychologie, Freud descreve três vivências primárias nas quais um som poderia participar da construção de significações. Essa tripla apresentação concordaria com a estrutura tripartida da linguagem exposta em Zur Auffassung der Aphasien, permitiria a ampliação do procedimento de constituição da significação da palavra apresentado parcialmente nesse primeiro texto e seria mantida depois na tripartição dos procedimentos de construção de significação do trabalho onírico. Reconduzimos, então, a polêmica sobre o limite da linguagem na teoria da psicanálise a apagamentos da multiplicidade de procedimentos de significação que reconhecemos em Freud, para, por fim, postular esses apagamentos enquanto método pertinente ao objeto mesmo da investigação psicanalítica.
\end{abstract}

Palavras-chave: Psicanálise, linguagem, significação, método.

ABSTRACT: The ear, the mouth and the eye: the psychoanalysis between the erasure and the recollection of speech places. In Entwurf einer Psychologie Freud describes three primary life experiences in which a sound could play a role in the building of meanings. This triple presentation agrees with the tripartite structure of the language exposed in Zur Auffassung der Aphasien; it allows an extension of the proceeding of building word meanings partly presented in that first text; and, later, it will be upheld in the tripartition of the proceedings of building the meaning in the dreaming work. Thus, we may reduce the debate about the limits of language in psychoanalytic theory to punctual erasures in the multiplicity of those meaning proceedings and finally postulate that these erasures constitute a method pertaining to the very subject of the psychoanalytic investigation.

Keywords: Psychoanalysis, language, meaning, method. 
— m Entwurf einer Psychologie (FREUD,1895/1987) Freud descreve três vivências

- primárias pertinentes ao contexto anterior ao estabelecimento do processo secundário da linguagem.

\section{O OUVIDO}

$\mathrm{Na}$ exposição da vivência de satisfação encontramos o primeiro deles. Freud escreve que o organismo, incapaz de sozinho realizar a ação específica que levaria à satisfação, depende do auxílio de um outro:

\footnotetext{
"pela descarga sobre um caminho de alteração interior, um indivíduo experiente percebe o estado da criança. Essa via de descarga adquire assim a função secundária, sumamente importante para a comunicação (Verständigung) e o inicial desamparo do ser humano é a fonte primordial de todos os motivos morais." (FREUD, 1895/1987, p.410) ${ }^{1}$
}

Freud não especifica nesse trecho a natureza do caminho interior percorrido como descarga, justificando a suposição de que, no limite, qualquer um poderia assumir a função de elemento de comunicação: movimentos de braços, sons, alterações faciais, etc. poderiam assumir essa função desde que um "indivíduo experiente" dispusesse dos meios para interpretar tal movimento como portador de um significado. A não-especificação da natureza do elemento significado apontaria implicitamente para uma concepção arbitrária deste, dependente apenas de sua recepção no interior de certo código e não de suas características inerentes. Contudo, ao retomar essa vivência na exposição que ele fará sobre o possível desenvolvimento biológico da linguagem na parte do texto dedicada aos processos normais, Freud iguala alteração interior e inervação lingüística (1895/1987, p.456-457). A fim de circunscrever por meio desse trecho a fala enquanto código arbitrário privilegiado na comunicação humana, definiremos como um som (grito ou choro) a alteração que é significada pelo outro experiente nessa primeira vivência.

\section{A BOCA}

A segunda referência encontramos na descrição de um processo judicativo que trabalha a partir da distinção entre parte da percepção comparável (predicado) e outra, incomparável (coisa). O processo é descrito como modo de compreensão de um semelhante e a medida do que é comparável aqui é dada pela imagem do movimento do corpo próprio. Freud escreve que “outras percepções de objeto,

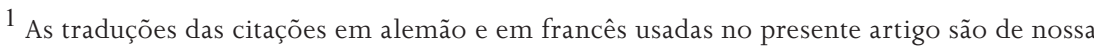
autoria.
} 
por exemplo, se gritam, despertarão a recordação do grito próprio e, com ele, de vivências próprias de dor" (1895/1987, p.426). O discernimento da percepção passa pelo reconhecimento no outro de um grito a partir do que posso reconhecer como meu grito - é porque o outro grita como eu grito quando tenho dor que posso atribuir uma qualidade a esse outro, posso compreender algo sobre esse outro.

\section{O OLHO}

A terceira referência descreve um processo associado à vivência de dor, mas não exclusivo a esta. Retomando o processo de compreensão como aquele que opera por uma distinção entre parte da percepção comparável e outra, incomparável, Freud reconhece aí a produção de dois enlaces para a operação da linguagem:

"em primeiro lugar, encontram-se objetos — percepções — que fazem gritar porque provocam dor, e é de grande importância que essa associação de um som (que também incita imagens de movimento próprio) com uma percepção assim composta ponha em relevo esse objeto como hostil e sirva para guiar a atenção sobre a percepção. Toda vez que, frente à dor, não se recebem bons sinais de qualidade do objeto, a notícia do próprio gritar serve para caracterizar o objeto (...) Existem outros objetos que de maneira constante produzem certos fonemas e dentro de cujos complexos de percepção um som desempenha um certo papel.” (FREUD, 1895/1987, p.457)

Freud opõe esse procedimento à associação "deliberada" de sons com percepções (linguagem enquanto processo secundário). Mas, pela tendência de imitação (Imitationstendenz), a imagem sonora poderia levar à reprodução da imagem motora correspondente ao som, procedimento que não estaria muito distante da invenção da linguagem - ou seja, ele ainda não é linguagem enquanto associação deliberada de sons, mas não está distante de sê-lo: "então não é preciso muito para se inventar a linguagem/fala (Sprache)” (FREUD, 1895/1987, p.457).

\section{I}

A história da linguagem é apresentada como uma somatória de vivências do sujeito. Freud postula modos pelos quais o sujeito adquire a linguagem como função comunicativa (segundo a interpretação proposta para a primeira vivência, som que é entendido pelo outro como mensagem), atributiva (som que atribui ao outro uma qualidade) e significativa ou representativa (som que significa um objeto do mundo). Em cada uma dessas experiências a ênfase está colocada em um elemento diferente: na primeira, importa o que chegaria ao ouvido do outro; na segunda, a imagem motora reproduzida pelo corpo próprio; na terceira, as 
percepções do objeto entre as quais se apresenta um som (quer produzido pelo próprio objeto, quer pelo corpo próprio como reação espontânea).

Encontramos nessa tripartição ecos de Zur Auffassung der Aphasien (FREUD, 1891/2001). Já nesse texto Freud postulara um modelo de unidade lingüística tripartida (composto por imagens sonoras, motoras e visuais) e, ao mesmo tempo, um acesso diferenciado à linguagem — cada sujeito passaria de um modo diferente pelos elementos que compõem a palavra. Por outro lado, os diferentes níveis de funcionamento da linguagem corresponderiam à multiplicidade de acessos à palavra. Em função disso, Freud pode concluir postulando três tipos de afasia: a afasia verbal, a afasia assimbólica e a afasia agnósica (FREUD, 1891/2001, p.148). Por fim, a crítica freudiana a Charcot traduz sua intenção de manter a tensão entre a diversidade dos elementos da linguagem, sempre necessariamente presentes, e a certeza de que a passagem diferenciada por esses não seria contrária à suposta preponderância do elemento acústico na sustentação das associações da linguagem (FREUD, 1891/2001, p.143-144).

Mas, para além desse eco, encontramos nas três experiências descritas em Entwurf elementos para a discussão de uma questão polêmica deixada em aberto por Freud no texto sobre as afasias: a questão da significação do complexo de palavra. Retomando o trecho em que Freud postula a formação da associação entre representação de palavra e representação de objeto como responsável pela significação, notamos que Freud escreve que "pelo menos para os substantivos" a significação se dá por essa associação. Ou seja, Freud não concebe essa como a única forma de construção de uma significação lingüística e, lendo a nota que ele acrescenta a esse trecho, encontramos a referência a um capítulo específico do livro de Stuart Mill que se intitula Sobre o nome das coisas (FREUD, 1891/2001, p.122). Trata-se, portanto, da exemplificação de um caso específico de significação, que não coincide de modo algum com a afirmação de uma exclusividade. Pelo contrário, se nos dedicarmos à leitura de todo o texto sobre as afasias, encontraremos Freud afirmando que a significação se dá via associação entre a representação de palavra e as representações da totalidade do córtex (FREUD, 1891/2001, p.134). Portanto, associações lingüísticas significativas poderiam ser dadas por outras representações que não seriam representações de objeto - e, de acordo com o que transcrevemos de Entwurf, por exemplo por notícias de movimento do corpo próprio (experiência da boca), ou pelo seu pertencimento a um código (experiência do ouvido que, concordando com o privilégio atribuído por Freud em Zur Auffassung ao elemento acústico na organização das associações lingüísticas, sustentaria, no limite, uma significação constituída apenas no interior do código).

Nas três experiências originárias descritas aqui poderíamos reconhecer três modos de construção da significação por meio do som: pela primeira, o 
som seria significado pelo código presente no outro; na segunda, o grito seria significado por um movimento do corpo próprio (o meu grito identificado ao grito do outro); na terceira vivência, o significado seria dado pela própria coisa do mundo (o som ou meu grito são qualidades do objeto). Apenas na terceira dessas vivências podemos reconhecer um exemplo primário de construção de significação tal como a descrita para os substantivos em Zur Auffassung der Aphasien. Enfim, as três vivências que recolhemos em Entwurf nos auxiliam a compreender a diversidade e a amplitude do que para Freud, de acordo com o caráter múltiplo atribuído à palavra, poderia estar em jogo na constituição de sua significação e que ele não chegara a desenvolver no texto sobre as afasias.

No texto sobre as afasias que Freud escreveu para o dicionário Villaret em 1888 encontramos outra vez uma concepção tripla da linguagem: "Diferencia-se a linguagem natural ou emocional, a linguagem gestual e a linguagem artificial ou articulada, entre as quais a última é mais freqüentemente exposta a perturbações, porque é a adquirida mais tardiamente" (FREUD, 1888/1983, p.42). Poderíamos ainda forçar a aproximação de cada uma dessas linguagens a uma das vivências descritas depois em Entwurf (respectivamente, linguagem do mundo/olho (natural), linguagem do corpo/boca (gestual — um gesto/grito atribui uma significação) e linguagem do código/ouvido (artificial ou articulada) e reforçar assim a hipótese de que para Freud, desde o começo, a linguagem foi reconhecida enquanto uma realidade múltipla.

Partindo do reconhecimento dessa multiplicidade em Freud, não poderíamos concluir, então, que o limite da linguagem, como pretende por exemplo J. Kristeva em sua análise de Zur Auffassung der Aphasien, estaria apenas na constituição dupla do signo freudiano, composto por representação de palavra e representação de coisa (KRISTEVA, 1980, p.63), nem apenas, como propõe Le Gaufey, na oposição entre o caráter fechado da primeira e o aberto da segunda, a qual inscreveria a incompletude no cerne da concepção freudiana de linguagem (LE GAUFEY, 1992, p.127 ). Lendo Zur Auffasung der Aphasien a partir da suposição de uma concepção tripartida da linguagem em Freud sustentamos que a linguagem é para ele já em si mesma, intrinsecamente, múltipla e não apenas um mesmo e único modo de dar conta do que lhe faria limite como heterogêneo.

A descrição em Entwurf da primeira dessas vivências está de acordo tanto com o papel privilegiado entregue à imagem acústica no texto de 1891 (posto que será essa o fundamento da significação sustentada apenas no código) como também já anuncia a estrutura que será depois concebida como fundamental através da postulação da castração. Primeiramente porque nessa primeira vivência Freud reconhece a origem da moral: ou seja, a linguagem que nascera aí é indissociável de uma submissão ao outro como lugar de significação e satisfação a ser atingido pelo sujeito (no limite, submissão ao código). Em segundo lugar, 
porque tal linguagem representa certo domínio sobre o corpo (em nosso recorte, o som tomado como alteração interna e descarga primária) para que ele possa ser utilizado não mais como descarga, mas como comunicação submetida ao outro. Enfim, tal como será na vivência de castração, uma significação dada pelo código no outro a certo movimento do corpo (por exemplo, a descarga sonora do choro) implicará um uso diferenciado desse movimento do corpo visando a manutenção do outro como lugar de satisfação. Se na experiência primária a satisfação dizia respeito à sobrevivência física, na secundária o visado é a satisfação de uma sobrevivência moral. Contudo, bastaria à psicanálise que nasce nesse momento manter apenas essa primeira vivência como correlata de sua concepção de linguagem?

II

Em 1900, Freud resume a três também os procedimentos empregados pelo sonho na construção da figurabilidade onírica: simbolismo, condensação e deslocamento (FREUD, 1900/1987). Jakobson associará diretamente esses três modos a três procedimentos lingüísticos subsumidos a sua oposição entre os pólos metonímicos e metafóricos da linguagem: a similaridade com que trabalharia o símbolo, correspondendo ao pólo metafórico, e a contigüidade com que trabalharia a metonímia e a sinédoque, correspondendo, respectivamente, ao deslocamento e à condensação (JAKOBSON, 1954/1963, p.65). Desse modo, o reconhecido por Freud como o trabalho propriamente onírico (condensação e deslocamento) é alocado no pólo metonímico da linguagem, enquanto aos procedimentos de figurabilidade sustentados pelo simbolismo — não concebido por Freud como procedimento exclusivo ao sonho (cf. FREUD, 1900/1987, p.354) — atribui-se um funcionamento metafórico. Assim, a distinção freudiana entre exclusivo ou não ao onírico é reproposta nos termos da distinção de Jakobson entre a significação dada pelo código ou pela metalinguagem. Retomemos, então, a partir do quadro proposto por Jakobson, as três vivências de Entwurf.

Na primeira vivência temos um funcionamento lingüístico que submete o sujeito a uma significação que se faz internamente ao código. Associa-se, então, a primeira vivência à metonímia, pois o significado do enunciado dependeria no limite apenas do que o outro como lugar de um saber lingüístico (da experiência de um código) faria deslizar internamente aos elementos do código. O caráter de deslocamento desse procedimento lingüístico estaria presentificado no próprio deslocamento do lugar da significação: ela não está no sujeito que enuncia, mas sim naquele que escuta. Nesse contexto, a segunda vivência primária (da boca) remeteria ao procedimento da sinédoque associado por Jakobson à condensação postulada por Freud. Constatamos que nessa vivência a significação se estabelece a partir de uma parte (o sujeito) que passaria a representar a totalidade da cate- 
goria (humana), ou seja, de uma generalização da parte para o todo (em outros termos, minha boca condensa uma significação sobre a natureza de todos os humanos portadores de semelhante boca). Atribui-se, assim, a capacidade a um de representar uma multiplicidade a partir da contigüidade entre corpos supostamente iguais. A terceira das vivências primárias retirada do texto freudiano e que denominamos de vivência do "olho" poderia ser comparada à formação do símbolo, na medida que há uma substituição pela qual um som que se apresenta como similar à presença de um objeto passa a representá-lo — portanto, o efeito de significação parece ser dado por um laço entre som e objeto, por uma referência no mundo no limite alheia à estrutura do código e não arbitrária.

Poderíamos concluir que já em Entwurf, ao descrever o que de lingüístico ocorre nas vivências primárias, Freud prenunciaria os três procedimentos de significação centrais a sua teoria da interpretação dos fenômenos psíquicos e que serão relocados posteriormente por Jakobson em uma teoria geral da linguagem. Contudo, a reacomodação proposta por esse último autor reconduz a tripartição freudiana a uma dualidade, subsumindo os três modos à oposição entre metáfora e metonímia. Portanto, no contexto das vivências primárias, o descrito como relação externa da linguagem (procedimento metafórico que exigiria a metalinguagem) estaria restrito à vivência do olho (mundo), enquanto a relação interna (metonímica, entre os elementos contíguos) comportaria as vivências dos elementos diretamente ligados à fala (ouvido e boca).

Em “L’instance de la lettre dans l'inconscient” (LACAN, 1957/1966) Lacan retoma a oposição que Jakobson traça sobre o ensinamento freudiano. Contudo, há um deslocamento na leitura lacaniana que não pode passar despercebido: diferentemente do lingüista, Lacan associa a condensação à metáfora e o deslocamento à metonímia: “a... condensação é a estrutura em que a metáfora toma seu campo... deslocamento é essa virada da significação que a metonímia demonstra” (LACAN, 1957/1966, p.269). ${ }^{2}$

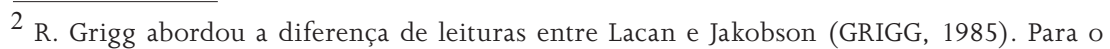
autor a questão de fundo que explica tal divergência é a definição de metáfora e sua diferenciação frente à metonímia, concluindo que Jakobson não dá conta do que seja a primeira. Embora Jakobson e Lacan buscassem ambos mostrar que são apenas as relações internas da linguagem que tornam possível a criação dessas figuras de linguagem (dos efeitos semânticos da contigüidade e da similaridade) ou, como quer Lacan, que tornam possível um efeito de sentido, a conclusão que cada um retiraria em relação a esse espaço de linguagem é distinta. Jakobson define o pólo metafórico como aquele que trabalha por substituição, associa a esse o simbolismo e a identificação freudianos e circunscreve um conceito de metáfora que é por definição metáfora por substituição, na qual os procedimentos se dão nas relações de linguagem, mas não são dados por essas - daí, o efeito de criação da metáfora. Contudo, para Lacan, aí onde estaria o símbolo de Freud e a metáfora por substituição de Jakobson, encontra-se a presença de um significante (phallus) que na linguagem indica o que não é senão falta de linguagem. Portanto, trata-se na leitura lacaniana de Freud de postular uma concepção de
} 
O que de Freud era compreendido por Jakobson no mesmo pólo metonímico da linguagem, como fenômenos de contigüidade, passa em Lacan a conter a própria oposição entre os dois pólos de funcionamento lingüístico, enquanto aquilo que em Jakobson se opunha a esses (a similaridade do símbolo) desaparece. Traduzindo essa passagem nos termos das três vivências que circunscrevemos em Freud poderíamos dizer que nesse texto de Lacan a linguagem é tomada apenas como o funcionamento do ouvido (código) e da boca (atribuição), os quais associamos respectivamente à metonímia e à sinédoque alocadas por Jakobson nos efeitos de contigüidade da linguagem. Trata-se, portanto, de uma leitura de Freud que, por assim dizer, internaliza os fenômenos de significação concebendo-os apenas a partir do que a lingüística de Jakobson reconhecera como os efeitos de sentido da contigüidade, colocando os dois pólos da linguagem onde esse lera em Freud apenas um deles.

L'instance de la lettre dans l'inconscient mostra-se um discurso esforçado em expulsar qualquer elemento discordante perante a máxima do inconsciente estruturado como linguagem, de acordo com a presente intenção de refundação do ensinamento de Lacan sob a égide da lógica do simbólico. Para tanto, a própria concepção de linguagem deve ser depurada de qualquer relação com o que não é ela mesma. Conseqüentemente, qualquer investigação sobre a origem da linguagem enquanto o que a precede, sem ainda ser linguagem, ou daquilo que a sustentaria desde um outro lugar que não ela mesma, poderia ser posta de lado e à compreensão das três vivências primárias como protótipos dos procedimentos de linguagem restaria o caminho do esquecimento parcial — bastaria, metodologicamente, reter a vivência da significação dada pelo código do outro elevado à condição de código do Outro.

Outro recorte incidiria sobre a distinção entre o signo ligado ao real e a linguagem enquanto "símbolo da comunicação ela mesma" proposta quatro anos antes em "Fonction et champ de la parole et du langage" (LACAN, 1953/1966) e que aludia a um 'referido' na linguagem. Recorte que também não manterá algumas considerações feitas nesse mesmo ano na pequena intervenção intitulada "O simbólico, o real e o imaginário", quando, após afirmar a investigação sobre a origem das línguas como "um dos temas que melhor pode se prestar a

metáfora que restrinja o lugar e a condição desse procedimento (o que nela se dá, mas não seria dado nessa) ao mesmo campo da linguagem e, desse modo, reloca toda a questão para o eixo que no limite é apenas aquele da contigüidade do significante - como indica o autor do artigo, Lacan mantém ortodoxamente a posição de Jakobson sobre a metonímia (GRIGG, 1985, p.22), mas passa a conceber também a própria metáfora enquanto uma substituição que se faz no eixo da contigüidade não em função de uma relação semântica dada entre conteúdos manifesto e latente, mas sim também como relação entre duas cadeias de significantes (em Lacan a metáfora se daria por uma dupla metonímia) (cf. GRIGG, 1985, p.24). 
delírios organizados”, Lacan se arrisca nesse tema justamente por meio de uma tripartição: a linguagem não é apenas a designação, mas também “senha” e "palavra chamada amor” (LACAN, 1953/2005, p.24-26) — há aqui um momento que, mesmo de forma crítica, relativiza o aforismo lacaniano sobre o fim da metalinguagem e no qual, como em Freud, encontramos uma origem tripartida para a linguagem. ${ }^{3}$

Uma investigação sobre a linguagem será em Lacan, portanto, tanto motivo de um percurso que a renega como também caminho pelo qual essa mesma poderá se inscrever em outro lugar: "Não há metalinguagem, mas o escrito que se fabrica da linguagem é material talvez forte o bastante para que aí se transformem nossos propósitos" (LACAN, 1971/2001, p.18). Mas, como tal percurso pode ele mesmo levar a psicanálise a esse lugar metodologicamente abandonado? ${ }^{4}$

\section{III}

Em “Sete proposições sobre o sétimo anjo”, Michel Foucault também descreve três procedimentos lingüísticos, reconstruindo a tripartição proposta por Deleuze - entre a linguagem que significa o sexual (neurótico), a linguagem que enuncia o sexual (perverso) e a linguagem que insufla o sexual nas palavras (psicótico) - a partir da análise de procedimentos lingüísticos reconhecidos em três autores e através da associação de cada um desses procedimentos a um certo lugar da linguagem no corpo, a saber, o ouvido, a boca e o olho (FOUCAULT, 1970/2001, p.20-24). Assim, Foucault reconhece em Brisset a falência do código à qual corresponderia a erotização do ouvido que concorda com o fracasso do funcionamento lingüístico desse - a fala vira ruído. Em Wolfson, a possibilidade de designação estaria recusada ao lado de um fechamento da boca para a função de lugar de enunciação - a palavra se imbrica na coisa. Em Roussel, a ruptura de significação ou interrupção do sentido ocorreria por uma dilatação dos olhos — o olho reconhece apenas a pura diferença.

Sobrepomos, então, as três dimensões da linguagem descritas por Foucault às três vivências descritas em Entwurf. Na primeira vivência, na qual o grito é

\footnotetext{
${ }^{3}$ A possibilidade de sobrepor as duas tripartições seduz: um olhar que designa; um ouvido que decifra; uma boca que doa a palavra. Mas, se a tripartição comparece em Lacan sob a forma das instâncias do simbólico, imaginário e real, será apenas com o auxílio dessas que poderemos indagar sobre tais procedimentos da linguagem.

${ }^{4} \mathrm{~J}$. Allouch buscará a reinscrição desse lugar em Lacan por meio da investigação da relação entre letra e signo, cuja ancoragem é dada também em uma tripartição da linguagem para a psicanálise que a decompõe em sentido, som e letra concorrentes com as funções do traduzir, transcrever e transliterar (cf. ALLOUCH, 1994). Para nós interessa investigar aqui se tal reinscrição implica um estatuto diferente para o que na história da psicanálise ficou sendo da ordem do que resta no conceito lacaniano de real a partir da retomada desse lugar através de um novo retorno a Freud - portanto, como veremos, da retomada da Bild e não da Lettre.
} 
significado pelo outro, temos a formação da significação por meio do código inscrito no outro e, portanto, uma prevalência do ouvido (daquele que ouve e significa). A falência do código repetiria a falência do ouvido, com a perda da função da imagem acústica na cadeia — tudo é puro ruído.

Na segunda experiência, na qual o grito do outro é significado pela atribuição de um mesmo movimento do corpo próprio, temos uma linguagem fundada na enunciação, quando a significação é capturada pela boca (daquele que grita e daquele que atribui por um movimento de sua própria boca uma qualidade a esse grito). O apagamento da função enunciatória corresponderia ao apagamento da boca enquanto capaz de um movimento motor que acrescenta algo ao outro - a boca se fecha e é incapaz de acrescentar um saber sobre o outro.

Por fim, na terceira experiência, quando a palavra parece fazer parte da própria percepção da coisa do mundo, ajudando a caracterizá-la, poderíamos reconhecer a linguagem de um sentido dado no mundo como percepção. A interrupção desse sentido representaria uma perda da função diferenciadora do olho na associação à produção do som e de sua escuta — nada pode ser fixado, designado, no mundo paralelamente ao som escutado e pronunciado. Enfim, é possível abordar o que está apagado em Brisset (o ouvido), em Wolfson (a boca) e em Roussel (o olho) para Foucault a partir das três vivências primárias descritas por Freud.

Lemos em Entwurf que o sentido atado ao som estaria originariamente ora submetido ao código, ora à atribuição, ora ao sentido — ora ao outro, ora ao corpo, ora ao objeto; ora no ouvido, ora na boca, ora no olho. No mesmo texto encontramos hoje indícios do privilégio da vivência que pressupõe o sujeito detentor do código para a formação da linguagem como processo secundário e de sua função como submetedora do sujeito à moral. A palavra que funcionaria apenas no código, descrita aí no modelo limítrofe de uma vivência primária, ganhará uma inequívoca importância teórica por intermédio da postulação da vivência de castração, que esboça com as cores da violência a fundação secundária da linguagem como consciência moral de si. Contudo, o reconhecimento desse telos não justificaria a redução da linguagem na psicanálise a essa dimensão final, a não ser que essa mesma assumisse falar apenas do lugar daquele que profere a ameaça de violência. Afirmar como fim último da teoria a elaboração de matemas concebidos como puro código está de acordo com a concepção de que o lugar da transmissão do saber é um lugar de violência. Mas nem todo lugar de saber para a psicanálise é aquele de sua transmissão.

A postulação da lalangue lacaniana, em contraposição à linguagem do puro código e de acordo com a memória da origem da linguagem que encontramos descrita em Freud, vem contrariar a restrição da psicanálise a esse lugar, reinscrevendo teoricamente a indagação sobre a origem da linguagem na história da 
psicanálise — para além da linguagem do código, repropõe o enigma daquilo que ainda não é, mas quase já é linguagem e do que a marca por uma verdade outra. A lalangue - enquanto berço da linguagem sem ainda ser linguagem, enquanto o que fornece as "cifras do sentido" da bateria dos significantes (LACAN, 1974, p.21), mas que permanece verdade "em ato, livre, sem cadeia” (MILLER, 1975, p.29) — rememoraria para a psicanálise as vivências primárias de Entwurf nas quais Freud descreve a linguagem ainda em sua qualidade de circuito primário. A polêmica, outrora imprópria, sobre os limites da linguagem é reconduzida, desse modo, a uma temática propriamente psicanalítica, na medida que é retomada através da história mesma de sua constituição. ${ }^{5}$ Mas bastaria, então, repropor a linguagem em sua suposta história? E o que poderia ser compreendido como tal história?

\section{IV}

Se, como quer Foucault, pelo apagamento dos lugares da linguagem não chegamos ao silêncio, mas sim ao barulho, ao espetáculo que se impõe pelos orifícios mesmos dos quais a linguagem foi retirada (FOUCAULT,1970/2001, p.24), para a psicanálise, comprometida com a verdade da decomposição intransponível de seu sujeito e de sua linguagem, a história concebida como apagamento temporal e pontual de procedimentos de significação assumiria a função de única metodologia capaz de gerar a reproposição dos diferentes lugares dessa(s) $\operatorname{verdade}(\mathrm{s})$.

No Seminário XXIII, Lacan diz que "a boa maneira é aquela que, por ter reconhecido bem a natureza do sinthome, não se priva de usá-lo logicamente, ou seja, de usá-lo até atingir seu real, em cujo termo ele não tem mais sede" (LACAN, 1975/2005, p.15). Trata-se, portanto, de não elidir o que seria o percurso lacaniano, mas sim de encontrar, na afirmação radical desse, aquilo que ele nos traz como verdade. Onde reconhecer, então, a radicalidade do movimento de conhecimento/estranhamento que Lacan traçou para a linguagem no interior do objeto da psicanálise?

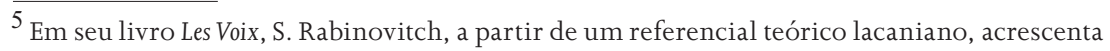
um terceiro tempo anterior à lalangue: a coisa (Ding) lacaniana retomada como bruitage, enquanto corpo sonoro inapreensível que persistiria em toda linguagem; o gozo da lalangue fundado na fonação que rompe e fura esse primeiro "barulhamento"; e por fim a separação entre som e sentido que dá origem ao significante no código (RABINOVITCH, 1999). Buscando o que há da linguagem em cada uma das instâncias lacanianas, a autora relê a máxima do inconsciente estruturado como linguagem ao repropor a instância do real e a do imaginário como elementos intransponíveis da própria linguagem. A autora, contudo, mantendo a distinção lacaniana entre sentido e real (cf. LACAN, 1975/2005, p.134), não põe em questão o que, metodologicamente, tal teoria sustenta como lugar de apagamento de significação.
} 
"Veiculei muitas dessas coisas que chamamos de freudianas (...) Mas nisso que chamo o real, eu inventei, porque isso se impôs a mim (...) É algo sobre o qual posso dizer que o considero como nada mais que meu sintoma (...) É na medida que Freud fez verdadeiramente uma descoberta — supondo que essa descoberta seja verdadeira - que podemos dizer que o real é minha resposta sintomática. Reduzir essa resposta a ser sintomático é também reduzir toda invenção ao sinthome." (LACAN, 1975/2005, p.132)

Se o conceito de real responderia em Lacan como sintoma que reinventa a verdade freudiana através de um apagamento metódico da linguagem enquanto procedimento que designa algo no mundo, ao propor um contexto teórico cujo ato mesmo de sua instituição permite prescindir de toda referência à suposta realidade, poder-se-ia concluir que, em relação aos três lugares de linguagem descritos aqui, a refundação lacaniana sustentaria sua verdade desde um lugar de fechamento dos olhos. Contudo, em sua qualidade de solução/sintoma, o que aí se apaga persiste e insiste:

“É porque o corpo tem alguns orifícios, dos quais o mais importante é a orelha, porque ela não pode se tapar, se cerrar, se fechar. É por esse viés que responde no corpo aquilo que eu chamei a voz. O embaraçoso é certamente que não há apenas a orelha, e que o olhar lhe faz uma concorrência eminente." (LACAN, 1975/2005, p.19)

Diferentemente de Lacan, para Foucault não apenas a orelha não poderia se fechar/silenciar e a tentativa de manter qualquer um dos orifícios da linguagem fechados/apagados levaria à potencialização de sua presença. No trecho transcrito aqui, Lacan inscreve como estrutural o apagamento e fechamento dos orifícios à exceção do ouvido e, a seguir, constata seu próprio embaraço perante um olho que insiste em não se fechar, em se fazer sempre presente: o olho, fechado, retorna sob a forma do embaraçante. Embaraço que, para além da função escópica concebida como sustentada na função paterna, portanto, no simbólico, marcaria a verdade do apagado do olhar pelo sintoma lacaniano de real. ${ }^{6}$

Indagando se a psicanálise poderia tensionar o nó que sustenta esse embaraçante, caberia retomar a leitura dos primeiros textos freudianos a fim de investigar os procedimentos de linguagem a partir dos conceitos de Bild — enquanto forma

\footnotetext{
6 Para Lacan, a impossibilidade está, portanto, em deixar de escolher um desses lugares de linguagem e eliminar o barulho que certamente restará em função dessa escolha. M. Certaux, em Le noir soleil du langage: Michel Foucault (2002, p.152-173), critica em Foucault justamente a ausência de marcação do lugar do qual se fala, contrapondo-a à posição assumida pela psicanálise segundo a qual, do mesmo modo como não se pode eliminar um desses lugares de linguagem, não se pode falar senão de um desses. Lacan, reconhecendo-se em um lugar, não desvia o olhar do embaraço que sua escolha produz.
} 
e não imagem — e de Vorstellung: o que é a imagem (Bild) que habita a origem do verbal enquanto elemento mínimo (Element)? O que mantém a unidade de um elemento denominado Bild e os diferencia em visuais, acústicos e motores? O que está implicado na associação pressuposta na passagem da imagem para a representação (Vorstellung)? (FREUD, 1891, p.117-122). O que significa o privilégio do acústico em sua qualidade de imagem (Klangbild) na construção da palavra? (FREUD, 1891, p.135). Qual a relação desse privilégio com a possibilidade de sua repetição como imagem de movimento do corpo próprio (eigene Bewegungsbild)? (FREUD, 1895, p.457). Enfim, a especificidade da imagem em Zur Auffassung der Aphasien e em Entwurf einer Psychologie não permite sua confusão nem com a sensação puramente orgânica, nem com a representação associada, e obrigaria sua inclusão como elemento constitutivo da linguagem por meio da particularidade da linha que atravessa imagem sonora/imagem de movimento do corpo próprio/representação. ${ }^{7}$

Trata-se, portanto, de investigar como a imagem compartilharia com a representação o lugar de verdade na linguagem para além daqueles da imagem do movimento do corpo próprio que engana e do resto visual que escapa. ${ }^{8}$ Se a história dos deslocamentos entre os procedimentos de linguagem põe em movimento a reafirmação de seus lugares heterogêneos de verdade, percorrer de

\footnotetext{
${ }^{7}$ Para responder a essas perguntas será preciso antes eliminar dois equívocos de leitura: supor entre representação e imagem uma relação pela qual a segunda ocupasse o lugar de referência externa da primeira; considerar a imagem como sinônimo de sensação. A imagem não se confunde com as sensações nem com a projeção (Projektion) dessas abrigadas por Freud no nível do funcionamento medular, portanto, fora do aparelho de linguagem. A imagem já é definida por Freud em oposição à projeção como um elemento de representação (Repräsentation) do corpo e, por outro lado, como elemento mínimo que não se confunde com a ordem associativa da representação (Vorstellung) (cf. FREUD, 1891/2001, p.93).

${ }^{8}$ Em "Linguagem e verdade em Abriss der Psychoanalyse" (Revista Olhar. São Carlos, maio/ junho 2006) argumentamos a favor da hipótese de que Freud aceitou até seus últimos escritos uma concepção dupla da verdade e do modo como a linguagem as coloca ao homem: uma construída pela linguagem, outra dada na linguagem. Nesse contexto, se representação e imagem ocupassem os dois lugares de verdade que reconhecemos como aqueles que Freud atribui à linguagem - concebidos, então, como correlatos ao procedimento do ouvido e ao do olho, à metonímia e à metáfora, ao simbólico e ao real - restaria atribuir ao procedimento da boca o lugar onde a linguagem se inscreveria como erro. O erro habitaria a linguagem onde a boca - pelo procedimento afim à sinédoque - atribui significação ao mundo, ao outro e a si mesmo através da inclusão de uma imagem específica: aquela do movimento do corpo próprio que repete a palavra ouvida transformando-a em representação, ou seja, o eu falante como elo de passagem entre imagem e representação. Compreende-se, assim, por que a resposta à verdade freudiana seria, como revela Lacan, sempre apenas um sintoma capaz de saciar por alguns instantes a sede de quem a propõe: tensionado pelas verdades portadas pela linguagem de seu ouvido e de seus olhos, cabe a esse sujeito de linguagem assumir o lugar da boca quando fala, lugar no qual lhe será dado acesso apenas ao erro de seu próprio movimento / percurso / sintoma / fala, posto que não poderá jamais coincidir com apenas um dos lugares de verdade de sua palavra.
} 
novo o traço da Bild tensionando o nó do sintoma lacaniano apresenta-se como momento de retorno do sentido mantido na origem mesma da palavra 'embaraço’: não só incômodo, mas também lugar fecundo de uma gravidez. Apagar o olhar será, então, metodologicamente, reapresentá-lo no embaraçante desse apagamento como prenhe de sentido.

Recebido em 8/5/2006. Aprovado em 21/8/2006.

\section{REFERÊNCIAS}

ALLOUCH, J. (1994) Letra a letra - transcrever, traduzir, transliterar. Rio de Janeiro: Companhia de Freud.

CERTEAU, M. (2002) "Le noir soleil du langage: Michel Foucault”, in Histoire et Psychanalyse. Paris: Gallimard.

FOUCAULT, M. (1970/2001) “Sept propos sur le septième ange”, in Dits et Écrits, v.II. Paris: Gallimard.

FREUD, S. (1888/1983) “Aphasie”, in Contribution a la conception des aphasies. Paris: PUF, p.41-45.

(1891/2001) Zur Auffassung der Aphasien. Frankfurt am Main, Fischer Verlag.

.(1895/1987) "Entwurf einer Psychologie”, in Gesammelten Werke. Frankfurt am Main, S. Fischer Verlag, Nachtragsband, p.387-477.

.(1900/1987) “Die Traumdeutung”, in Gesammelte Werke. Frankfurt am Main, S. Fischer Verlag, v. II/III.

GRIGG, R. (1985) Jakobson et Lacan. Ornicar?, n. 35. Paris: Navarin, p.12-34.

JAKOBSON, R. (1954/1963) "Deux aspects du langage et deux types d’aphasie”, in Essais de linguistique générale. Paris: Editions de Minuit.

KRISTEVA, J. (1980) Pouvoirs de l”horreur. Paris: Seuil.

LACAN, J. (1953/1966) “Fonction et champ de la parole e du langage”, in Écrits I. Paris: Seuil. .(1953/2005) “O simbólico, o imaginário e o real”, in Nomesdo-pai. Rio de Janeiro: Jorge Zahar. . (1957/1966) “L 'instance de la lettre dans l'inconscient”, in Écrits I. Paris: Seuil.

(1962/2004) Le séminaire livre X, L’angoisse. Paris: Seuil. .(1971/2001) “Lituraterre”, in Autres écrits. Paris: Seuil. (1974) Télévision. Paris: Seuil.

(1975/2005) Le séminaire livre XXIII, Le sinthome. Paris: Seuil.

LE GAUFEY, G. (1992) L'incomplétude du symbolique. Paris: Epel.

MILLER, J.-A.(1975) Theorie de lalangue. Ornicar?, n.1. Paris: Le Graphe, p.16-35.

RABINOVITCH, S. (1999) Les voix. Paris: Erès.

Alessandra Caneppele

frasp@iel.unicamp.br

Ágora (Rio de Janeiro) v. X n. 1 jan/jun 2007 61-74 